\title{
INCIDÊNCIA DE Fusarium solani EM MANDIOCA NO ESTADO DO PARÁ
}

\author{
LUIZ S. POLTRONIERI ${ }^{1}$, DINALDO R. TRINDADE ${ }^{1}$, FERNANDO C. ALBUQUERQUE ${ }^{1}$, \\ MARIA L.R. DUARTE ${ }^{1} \&$ SHIRLEY. S. CARDOSO ${ }^{2}$
}

\author{
${ }^{1}$ Embrapa Amazônia Oriental, Tv. Dr. Eneas Pinheiro, s/nº, CEP 66095-100, Belém, PA, e-mail: \\ poltroni@cpatu.embrapa.br; ${ }^{2}$ Faculdade de ciências Agrárias do Pará, Av. Perimetral, 2501, Belém, PA
}

(Aceito para publicação em 29/07/2002)

Autor para correspondência: Luiz S. Poltronieri

\author{
ABSTRACT \\ Incidence of Fusarium solani in cassava in the State of Pará, Brazil \\ This paper describes for the first time the occurrence of Fusarium solani infecting cassava (Manihot esculenta) in the State of Pará.
}

Durante o mês de agosto de 2001, observou-se em áreas de produtores localizadas no município de Santarém, PA, a incidência de uma doença causando a morte de $30 \%$ de mudas de mandioca (Manihot esculenta Crantz) da variedade conhecida na região por Olho de Boto. Os sintomas típicos da doença são caracterizados pelo apodrecimento do coleto, causando amarelecimento e murcha das folhas, culminando com a morte das plantas. Dos tecidos lesionados do colo da haste foram retirados pequenos fragmentos, desinfestados em $\mathrm{NaOCl} 0,1 \%$ lavados em água esterilizada e plaqueados em meio ágar-água. Após três dias, desenvolveu-se um fungo que em meio de BSA (batatasacarose-agar) apresentou colônias circulares, contendo micélio flocoso abundante, de coloração branca a violeta claro e pigmentos de coloração violeta. Os macroconídios são falciformes alguns quase retos, formados em monofiálides longas sobre hifas, medindo $41,8 \mu \mathrm{m}-15,4 \mu \mathrm{m}$ x $6 \mu \mathrm{m}-4,4$ $\mu \mathrm{m}$, com 3 a 4 septos, pouco numerosos. Produz abundantes microconídios em falsas cabeças, elípticos, medindo $11 \mu \mathrm{m}-$ $4,4 \mu \mathrm{m} \times 4,4 \mu \mathrm{m}-2,2 \mu \mathrm{m}$, clamidosporos a maioria agrupados e alguns isolados em culturas com mais de 20 dias de idade, cujas características correspondem ao fungo Fusarium solani (Mart.) Sacc. Para se comprovar a patogenicidade deste isolado realizou-se inoculação em mudas da cv. Olho de
Boto com 30 dias de idade, obtidas através do sistema de propagação rápida (Lozano et al. Ciat.1:20, 1976). Mudas de mandioca com as raízes previamente feridas foram imersas em uma suspensão de $10^{6}$ conidios $/ \mathrm{ml}$. e logo após, plantadas em copos de plástico de $14 \times 9 \mathrm{~cm}$, contendo solo esterilizado. $\mathrm{O}$ inóculo foi obtido cultivando-se o fungo em meio de BSA sob luz contínua e temperatura de $28{ }^{\circ} \mathrm{C}$, durante uma semana. Foram deixadas mudas como testemunha, as quais sofreram o mesmo processo de ferimento em raízes, sendo o inóculo substituído por água. Todas as plantas inoculadas pelo fungo foram infetadas e mortas, enquanto que as testemunhas mantiveram-se sadias até 30 dias após a inoculação. Na literatura os relatos dessa doença são atribuídos a Fusarium spp e F. solani (FUKUDA, 2000. Principais doenças da mandioca. In: O Cultivo da Mandioca. Embrapa Mandioca e Fruticultura, 2000. p.6578. Circular Técnica, 37; TAKAHASHI et al. Ocorrência da Podridão no Oeste do Paraná. In: X CONGRESSO BRASILEIRO DE MANDIOCA. Manaus, AM. 1999. pp.63.) Este é o primeiro registro do ataque de F. solani em mandioca no Estado do Pará. O isolado encontra-se depositado na micoteca da Embrapa Amazônia Oriental.

Os autores agradecem a Prof. Dr ${ }^{\mathrm{a}}$ Maria Menezes pela identificação do fungo. 